\title{
Royal College of Nursing (Rcn) code of professional conduct: A discussion document
}

We are printing in its entirety the discussion document which sets out a code of professional conduct for nurses published by the Royal College of Nursing in November 1976 together with commentaries by the Assistant Secretary of the British Medical Association, a professor of nursing studies, student nurses and a lawyer.

The image of the nurse is still that of one of Florence Nightingale's young ladies or of a member of a religious order who is wholly dedicated to caring for the sick. Today, as this document and the comments upon it show, 'dedication' is still part of the motive which leads a man or woman to become a nurse but in addition, and this is where the public may be ignorant or choose to be ignorant, nursing offers a career where intellectual achievement and the satisfaction of a demanding job bring their proper financial reward and place in the professional community.

We are grateful to the Royal College of Nursing for permission to publish this document.

Text

I INTRODUCTION

The profession of nursing has a commitment which is shared with other health care professions to promote optimal standards of health, combat disease and disability and alleviate suffering. A code of professional conduct is required in order to make explicit those moral standards which should guide professional decisions in these matters, and in order to encourage responsible moral decision making throughout the profession. It is recognized that no code can do justice to every individual case and therefore that any set of principles must remain constantly open to discussion both within the nursing profession and outside it.

\section{Discussion}

I The starting point of this code is the recognition that nursing is now a profession in its own right, with all the responsibility which that entails. It shares with other professions - notably medicine and social work - the goal of improving the health prospects of all members of that society which grants it the right to practice. Because ideas about health goals vary from individual to individual, and because nurses have considerable influence (and on occasion power) over patients or clients whose needs and handicap often render them especially vulnerable, a code of conduct is needed to provide guidelines for professional practice. Such a code ought to be continuously developed and refined by sustained discussion among nurses themselves, and by consultation between nurses and those who can speak for other professions and for the general public.

Codes are never a substitute for personal moral integrity, and they can often be hardened into legal formulae. It must therefore be stressed that the purpose of this code is not to devise grounds for disciplinary proceedings (or any similar purpose), but rather to provide a clear and comprehensive document for further discussion, particularly during periods of professional training. 
II RESPONSIBILITY TO PATIENTS OR CLIENTS

The primary responsibility of nurses is to protect and enhance the wellbeing and dignity of each individual person in their care. As members of professional teams nurses should recognize and accept responsibility for the total effects of nursing and medical care on individuals. This responsibility is in no way affected by the type of origin of the person's need or illness or by his age, sex, mental status, social class, ethnic origins, nationality or personal beliefs. Therefore it follows that:

I) Nursing care should be directed towards the preservation, or restoration, as far as is possible, of a person's ability to function normally and independently within his own chosen environment.

2) Discrimination against particular individuals, for whatever reason, should never be tolerated.

3) During episodes of illness the autonomy of patients should be maintained throughout treatment, restrictions being imposed only when these are demonstrably necessary for their own wellbeing, or for the safety of others; and the active participation of patients in their own treatment should be facilitated by means of open and sensitive communication.
I) As a form of social occupation nursing serve $\underline{\vec{\Omega}}$ several ends: it provides paid employment to a large section of society; it gives individuals a sense $\triangle$ intellectual achievement and job satisfaction; and offers congenial and rewarding inter- and intraj professional relationships. But none of these should take precedence over the primary end of nursing which is to enable people to live their own lives as fully and freely as possible by providing professiona counsel and care according to particular needs.

2) Entering the nursing profession involves commitment to the service of persons, each of whon merits individual respect. At times nurses may have prejudices against patients or clients because thes consider that they are largely responsible for their own misfortune or because they cannot feel iny sympathy for their particular form of distress. the adoption of a professional attitude requires that all those who need nursing care should receive without discrimination. No group of patients of clients should be regarded as unworthy or undeserv ? ing of professional concern.

3) Nurses share in responsibility for the effect of the multidisciplinary treatment methods of modern medicine on personal health and freedom. In particular, the routines of hospitals and health institutions and other organizational structures maye. unnecessarily remove the dignity and independence of patients, thereby diminishing their overall health prospects. In view of this a fundamental aspect of the nurse's responsibility to the patient can be seen? as the maintenance and restoration of personato autonomy. This is principally achieved by skilled nursing care of each individual, with an under- -0 standing of the context of his illness or disabilityn and with careful attention being paid to communi-N cation with him, especially during periods of anxiety. In this context it should be noted that the best source of information about the patient is $ᄃ$ usually the patient himself and that regular and relaxed discussions with relatives can increase the nurse's understanding of the patient's circumstances and of possible ways in which he can be helped to $\mathbb{D}$

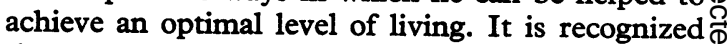
that dealing with violent or potentially violent $\frac{a}{\sigma}$ 
4) Measures which jeopardise the safety of patients, such as unnecessary treatments, hazardous experimental procedures and the withdrawal of professional services during employment disputes, should be actively opposed by the profession as a whole.

5) Information about patients or clients should be treated with the utmost confidence and respect, and should not be divulged to persons outwith the primary care or treatment team without the person's consent, except in exceptional circumstances.

\section{RESPONSIBILITY FOR PROFESSIONAL STANDARDS} The professional authority of nurses is based upon their training and experience in day-to-day care of ill persons at home or in hospital; and in the enhancement of positive health in the community at large. All members of the nursing profession have a responsibility to continue to develop their knowledge and skill in these matters. patients raises particularly difficult problems in relation to restraint and patients' freedom. It is essential that clear guidelines are given to all those who have such patients in their care to ensure that prejudice and mutual fear between patients and staff do not worsen the situation (see the guidelines offered by the DHSS on the basis of joint advice from the Rcn and the Royal College of Psychiatrists - The Management of Violent or Potentially Violent Hospital Patients. HC(76)II).

4) Actions which betray people's confidence in the professional integrity of nurses diminish the ability of the profession to be of help. For this reason the nursing profession should be clearly seen to be opposed to exploitation of vulnerability: for example, treatment and experimentation, inappropriate treatment, risky experimentation or experimentation without proper consent; or industrial action, the removal of professional services which put patients at risk.

Although choice of treatments and the initiation of clinical research projects is usually solely a medical responsibility, nurses have the right and the duty to express opinions about the effect of such procedures on the patients under their care. (For instance, a nurse may question whether the dignity of a dying patient is being respected by procedures employed to delay death; and the design of an experimento involving discomfort or risk to patients may be questioned by nurses asked to cooperate in the experiment.)

Nurses are entitled to equitable wages and conditions of employment and should be free to enter into appropriate negotiations with their employers. But since seriously ill people are in no position to protect themselves when professional aid is withdrawn, disruption of services by strike action and threats to do so contravene the nurse's commitment to service of patients and should be publicly opposed whether the action is carried out by nurses or by other professions and occupations involved in health care.

5) In unusual circumstances it may be necessary to disclose confidential information for the wellbeing of the patient or others in the nurse's care, but this should never be done without full consultation with relatives and with medical and nursing colleagues; and whenever possible the patient should be told why such a disclosure was felt to be necessary.

III The claim to professional status implies that nurses have particular forms of knowledge and skill in health care which are not shared by other professions and which thereby give them the authority to institute nursing procedures and make decisions and recommendations about correct nursing care.

This claim must be substantiated by the profession as a whole through the establishment of 


\section{RESPONSIBILITY TO COLLEAGUES}

In general, relationships with colleagues in nursing and in other health care professions should be determined according to what will maximize the benefit of those in their care.

I) Professional relationships between nurses should be regulated according to the level of knowledge, experience and skill of each nurse. Clear chains of command should be established to deal with emergency situations, but except in such situations, free discussion of the reasons for established procedures should be encouraged at all levels.

2) Professional relationships between nurses and doctors should be regulated according to the particular expertise of each profession. In the case of medical treatments nurses are under an obligation to carry out a doctor's instructions except where they have a good reason to believe that harm will be caused to the patient by so doing. In cases in which nurses' continuous contact with the patient has given them a different insight into the patient's medical needs, they are under moral obligation to communicate this to the doctor in charge of the case. Nurses should support the multidisciplinary case-conference approach to treatment decisions, and should improve their ability to participate actively in such conferences.

3) Professional relationships between nurses and members of other health care professions should be based upon respect for each other's area of expertise and on the desire to gain a fuller understanding of the patient's or client's needs. Procedures should be established for regular inter-professional consultations. training procedures and the maintenance of coms petence at all levels within the profession and b9 continued research into new and improved methods: of nursing care.

Individual nurses have the responsibility to be self-critical of their professional performance and t $\overrightarrow{\mathrm{d}}$ seek to adapt it to changing needs and new tech niques of care.

IV The goal of 'whole person treatment' determine how nurses should relate professionally to theis fellow nurses and to members of other health cart professions. It is assumed that the more there is cooperation and communication between the different people caring for the patient, the more the patient's needs are likely to be understood and catered for. (As noted in the previous section, the patient himself has also a great deal to contribute tọ such full understanding, as do his relatives.)

I) The nursing 'hierarchy' can be seen to be् necessary to ensure that decisions are taken by those who should have the requisite knowledge and experience, but on the other hand junior members of staff can often bring fresh insights about patient? or be more successful in gaining the patient's confidence. For this reason an atmosphere of friendly questioning and discussion between staff at different levels can improve the quality of carecas? well as making nurse education more effectipe. (Obviously clear lines of authority are needed tof situations in which rapid decisions have to be made.

2) Nurses are not trained to diagnose illness or t@ prescribe medical treatment. They must therefore normally carry out doctors' instructions in these matters and help maintain the patient's confidence in his medical advisors. But nurses are in a uniques position to observe the condition of the patient at all hours of day and night and have received basic instruction in drug dosages, effects of treatment, etc.్ㄱ For this reason they are morally obliged to question medical instructions which they believe will cause the patient harm or unnecessary distress (see section II) even though they may fear adverse effects on? their career from doing so. Ideally, however, thiso should not entail a confrontation between doctor? and nurse, but should arise naturally in the contexto of ongoing inter-professional discussions in case conferences. Part of the professional training of 0 nurses should prepare them to take part in such conferences from their own professional standpoint N

3) In the case of other professions which maye have contact with patients or clients (eg, paramedical professions, social workers, hospital chaplains and other clergy) nurses should be concerned to establish ${ }^{+}$ relationships of trust. This should promote a mutualo understanding of professional roles enabling the patient/client to derive maximum benefit from the work of the caring team. 


\section{PROFESSIONAL RESPONSIBILITY AND PERSONAL RESPONSIBILITY}

As citizens of a state and as private individuals nurses should defend and actively pursue those moral values to which their profession is committed, namely, individual autonomy, parity of treatment and the pursuit of health. In some circumstances this may require protest against, and opposition to, social and political conditions which are detrimental to human wellbeing; and in others, the altering of personal habits which set a poor example in health care. In all other respects nurses have the right to regulate their private lives according to their own standards of morality, provided their style of life does not cast doubts on the integrity and trustworthiness of their profession.

\section{Commentary}

\section{J D Dawson British Medical Association, Tavistock Square, London}

\section{Origins of ethical codes}

In the climate of opinion in which we find ourselves at the moment I suppose it was inevitable that there should appear from the Royal College of Nursing a discussion document setting out a code of professional conduct for nurses. The text of the code, and the associated discussion have a number of interesting facets but before examining the code in detail I think it may be useful to look briefly at the origins of ethical codes in general.

\section{GENERAL PREMISES}

Structure and organization in some form is a premise of any society and the majority of individuals within a society recognize that the rights conferred and duties exacted by social institutions are mutual. In other words, a major reason for the success of a society is the individual's awareness that it is to his
$\mathrm{V}$ Because nursing finds its origins partly in religious orders, there may be unrealistic expectations both within the profession and among the general public about the degree of personal dedication to which modern nurses should aspire. Like other professionals, nurses have the right to conduct their private lives without undue interference from colleagues or employers. Also like other professionals, however, the choice of a personal service career commits the nurse to certain moral views. Nurses cannot strive to alleviate disease and suffering without becoming aware of the social circumstances which bring it about or which inhibit the provision of effective remedies. It follows that nurses should be concerned with political and social issues, whenever these are relevant to the prevention of disease or the delivery of health care. Similarly in the sphere of personal conduct, nurses should strive to 'practise what they preach' to avoid personal habits which are known to be detrimental to health. (For example, doctors and nurses are particularly at risk for drug and alcohol addiction a factor which seems to demand closer supportive attention from their respective professions.)

In addition to setting a good example in healthy styles of life, nurses need to inspire confidence in patients in order to be able to help them fully. This does not imply 'angelic' purity of life - merely the following of standards of honesty and of moral seriousness which would be expected from any member of society who has responsibility for the welfare of others.

ultimate advantage to comply with the requirements of that society.

Moral codes are like other demands made upon members of a social organization and it is important to recognize that these demands will change with the changing conditions that the organization experiences. The ethical principles of the group will lie within certain universal prohibitions and requirements but are secondary to the established behaviour of the group. The importance of the latter point cannot be overemphasized; ethical principles and rules have no independent existence of their own, they occur subsequently to experience and are crystallized out of established patterns of behaviour.

Ethical codes that have evolved from the experiences of a society or a group of people invariably contain sanctions against individuals whose behaviour is incompatible with the requirements of the code. Tradition, social approval or ostracism and economic penalties are all effective sanctions used to enforce moral rules and ethical codes.

RCn PROFESSIONAL CODE

I have both applause and regret for the paper from the Royal College of Nursing. Taken paragraph by 
paragraph, the injunction against discrimination in the second paragraph of section II is obvious but nevertheless praiseworthy, and the encouragement for the individual to maintain his or her own standards by continuing self education must be an integral part of the development of any professional.

The text of paragraph 3 , section II, is broadly aligned with the current opinion that patients should be encouraged to take a greater share of the responsibility for their own health. I think it is an acceptable extension of this philosophy to promote the autonomy of a patient, as far as possible, in a period of illness. Curiously this view is in accord with Illich writing in the introduction to Limits of Medicine' : 'In part at least, the health of a population depends on the way in which political actions condition the media and create those circumstances that favour self reliance, autonomy and dignity for all, particularly the weaker. In consequence, health levels will be at their optimum when the environment brings out autonomous personal, responsible coping ability'.

Deprived of Illich's theological background the British Medical Association was blunter in its evidence to the Royal Commission': 'Far more attention should have been given to developing a sense of responsibility in the proper use of the Health Service.... We urge appropriate health education directed towards the individual's own sense of responsibility for health.'

Paragraph 4, section II, is, I believe, well meant in intention but confusing in effect. Black and white cases are easy to deal with; if more nurses thought carefully about the actions and prescriptions of doctors with whom they have not worked before, there would be fewer cases of locum 'doctors' turning out not to be registered medical practitioners. Unfortunately most of real life lies within a grey area where responsibility, individual expertise and beliefs are combined in a complex interaction. In this context I agree entirely that nurses have the right and duty to express opinions about the effect procedures may have on the patients under their care but surely only a small minority of nurses would care to make definitive statements about whether or not particular forms of treatment are inappropriate or whether or not a clinical experiment is unnecessarily risky. The controlled trials that were eventually done on streptomycin in the treatment of tuberculosis is an obvious example of balanced risk and benefit. Until the outcome of the trials was known even the designers of the trial procedures with an overview of the whole were unable to make an informed judgment.

The major criticism of the document must be, however, that it is not based on present, established nursing patterns of work. The paper appears to be not so much an attempt to set down a moral code for nurses, essentially a conservative exercise, as a radical revision of the boundaries between nursing care and other workers' spheres of action within the health service. Patients also participate in the healtho service and there are sections of the document that relate less to the needs of patients than to those of the nursing profession. For example, a person who'? is sick tends to regress slightly in behavioura terms, wishing to hand the responsibility for his? restoration to good health to another person Usually the doctor is the person who accepts the responsibility for the patient's restoration to goop health, and I believe that for the benefit of the patient it is necessary for there to be a clear role fon the doctor as the leader of a group of people providing care for the patient. It is for this reasonthat $I$ believe the multidisciplinary team approactu fails when it is combined, as is now common, with decision making by consensus.

Darwin said that form must follow function and events will show whether or not the Royal College of Nursing has cast its professional code in a mould that the nursing profession will subsequently fito If it has, the result will be owed partly to a lack of able leadership by the medical profession. $\overrightarrow{5}$ believe that the Royal College of Nursing has produced a political document, a manifesto of a sort seeking to lead or push nurses into unrecognize patterns of work. This discussion document map indicate the way to an inevitable future, but regret that I do not think the patients will of better served in that future.

\section{References}

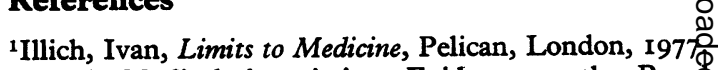
${ }^{2}$ British Medical Association, Evidence to the Roya Commission on the National Health Service $\vec{B}$ London, 1977.

\section{A T Altschul Department of Nursing Studies, University of Edinburgh}

\section{On whose authority?}

The value of a discussion document inevitably depends on the authority of those who issue it, on the composition of the group which discusses it and on the sphere of influence of those who are in position to disseminate their view. N

This document lacks any reference to the authority of its authors and consequently loses much of the impact it ought to have. It is simply not goo@ enough to print an undated, unsigned and une explained 'code of conduct' presumably in the belief that the letters ' $R \mathrm{cn}$ ' command bling obedience.

The International Council of Nurses (ICN) has already formulated a 'code of ethics' which consisti of a mixture of a description of the role and function of nurses and a codified pious hope. In so far as the 
prescriptive statement refers to 'moral' values, it does not help nurses to identify what behaviour would meet the commands. For example, 'the nurse should at all times maintain standards of personal conduct which reflect credit upon the profession'. What conduct would do this and why is it important ?

This discussion document avoids the traps the ICN has fallen into. Reading the text vertically there are statements about the essence of nursing with which few would quarrel: given that one accepts the introductory statement that nursing has a commitment to promote optimal standards of health, the list of what nurses should and should not do follows logically. The document goes further, though, than to enunciate what nurses should do. It declares that some of the nurses' actions need to be guided and evaluated by moral standards and then proceeds to discuss what these moral guidelines are. Reading the two columns horizontally helps the nurse to consider specific examples of moral issues and appropriate behaviour.

\section{The autonomy of patients}

For many nurses the section on the autonomy of patients will be of special concern. The document discusses situations in which this may not be possible, for example, in the case of potentially violent patients or of those whose behaviour endangers their own safety.

I should like nurses to think deeply about the significance of autonomy in people's lives. The psychologist Erikson ${ }^{1}$ may be right when he says that the achievement of autonomy is the proper developmental task of the toddler at the time when he gains muscular and anal control. He believes that failure to achieve autonomy results in the experience of shame and doubt. Erikson does not say what happens if later in life muscular and bowel control is lost, but nurses can readily observe in patients who are incontinent, who need to be assisted with every movement of limbs, or whose movement has to be restricted, how devastatingly they experience shame and doubt.

Of course nurses should strive to support the autonomy of patients at all stages of illness. But, perhaps they must also learn the more difficult task of assisting patients to accept help and control without shame. Unwittingly nurses may be participants in fostering the humiliating routines of hospitals which Goffman ${ }^{2}$ has so aptly identified as institutional life. They will have many opportunities, not only for removing constraints, but for helping the patient to accept these with dignity.

With mentally disturbed patients increased self respect may be a powerful factor in reducing disturbed and violent behaviour. Guidelines of the kind the Ren and the Royal College of Psychiatrists have issued are needed to deal effectively with emergencies $^{3}$. As soon as the emergency is over, nurses and patients need to repair the damage which may have been done to the autonomy of both.

\section{Concern of nurses with social and political issues}

It is refreshing to read in a document of this kind that nurses are not expected to live a life of 'angelic' purity and that they have the right to conduct their private lives without undue interference, indeed that they should be concerned with political and social issues whenever these are 'relevant to the prevention of disease and the delivery of health care'. It would seem difficult to think of any social or political issue which fails to quality on those criteria.

I welcome the explicit admission that nurses and doctors or other coworkers may at times find themselves on different sides of a fence and that relationships between nurses and members of other professions should be based upon respect for each other's area of expertise. I subscribe wholeheartedly to the belief that procedures should be established for regular interprofessional consultation. I agree that nurses should be concerned to establish relationships of trust. How this is to be achieved is unfortunately not described. The main objective of interprofessional discussion groups must therefore be to address themselves to the task of developing trust and respect.

\section{References}

'Erikson, E H, Childhood and Society, Harmondsworth, Penguin, 1965 .

${ }^{2}$ Goffman, E, Asylums, Harmondsworth, Penguin, 1968.

${ }^{3}$ Royal College of Nursing and National Council of Nurses, The Care of the Violent Patient, Report of the Liaison Committee with the Royal College of Psychiatrists, 1972.

\section{Chris Sampson Rcn Student Association Officer, London*}

\section{Some students' contributions}

Many students thought that there should be more emphasis placed on new social and socio-political conditions in our society.

They considered that the poor staffing situation, which has become a way of life in most British hospitals and community services, does not always allow nurses sufficient time to give the full amount of attention to both the patient's physical and mental wellbeing. Pressure of work can lead to an apparent lack of sympathy.

*The views expressed are not necessarily those of the Rcn Association of Nursing Students or the Royal College of Nursing. 


\section{INDUSTRIAL ACTION}

On the subject of industrial action most students think that they have a duty to ensure the safety of patients when colleagues or other health care workers withdraw their labour. A few thought that it might be necessary to withdraw their labour in extreme situations when improvements in standards of care are denied by employing authorities. This action would only be contemplated in extreme situations and only in units where patients' lives would not be at risk, for example in day hospitals.

\section{PROFESSIONAL STANDARDS}

The students thought that the responsibility for professional standards in nursing must rest with nurses. They also considered that 'at home or in hospital', in the context of health care patterns, was a limited view of a much wider range of nursing activities.

\section{RESPONSIBILITY TO COLLEAGUES}

As a profession, nursing is less mature than many, and there is a great need for expansion and definition of roles within nursing to come from within the profession. A good team relationship is based on respect and nursing students should be treated as team members. Their lack of experience is not disputed but they are in training for a professional qualification and are not just an extra pair of hands. The statement that free discussions for established procedures should be encouraged was welcomed. For too long hierarchical structures have prevented a development of the 'questioning attitude' which is so overdue in nursing.

\section{PROFESSIONAL RELATIONSHIPS}

This section caused concern as it appears to limit the development of discussion about the autonomous role of nurses in certain areas of practice.

\section{PERSONAL RESPONSIBILITY}

On the subject of personal responsibility many students believe that so long as the nurse's ability to work effectively is not impaired her private life should remain outside the purview of employers and managers.

\section{Alexander McCall Smith Faculty of Law, University of Edinburgh}

\section{Cessation of treatment, autonomy and consent}

Like others in the medical and associated professions, nurses are obliged to operate under the shadow of the civil and criminal law. Frequently this shadow is ill defined; the legal position may be clear on some matters, but on others there may be some un- certainty as to what the law is. This may be explaine

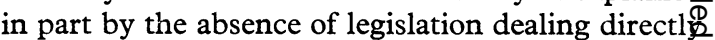
with the professional responsibility of the nurse orm the doctor, but it is also a result of the curiou circular relationship between law and medicine? The law may ultimately be called upon to defin what is acceptable conduct on the part of the professions, but it tends to do so on the basis of what the professions themselves suggest. The law then, looks for guidance to professional consensus while the professions naturally look to the law for a statement on what they can or cannot do. In these circumstances the promulgation of a code क्ष professional conduct is of major legal significance, in that it can be influential in the moulding of legad attitudes.

From the legal point of view the fundamentad responsibility of the nurse, as stated in section Iq of the Code, is unexceptionable. It might be interesting, however, to speculate as to what subtl differences there may be between the expression 'well being and dignity of each ... person' (the terms used in the Code) and the expression 'the lifes of each patient' (not used in the Code). Here there raised a fundamental problem of legal responsibilit $\$$ that undoubtedly presents real and sometimes agonizing dilemmas for many nurses. The law doe not allow euthanasia, nor, in the practice's mor $\vec{\theta}$ obvious or objectionable forms, does the presenty moral consensus condone it. Yet nurses daily the problem of the not-to-be resuscitated patione the deformed baby which is not given medit treatment it may require to stay alive, or thi geriatric patient who is not given antibiotics to combat an infection. These instances of passive euthanasia can theoretically lead to both crimina and civil liability on the part of the nurse as much as on that of the doctor. The nurse who condones of assists in the cessation of treatment (where the treatment falls into the category of 'ordinary' a opposed to 'extraordinary' treatment ${ }^{1}$ ) might i $\mathrm{i}$ theory be prosecuted for culpable homicide (manslaughter in England). The practical likelihoo of such prosecution is slight, particularly in countrie where the decision to prosecute is reserved to official prosecutors, but the possibility still exists? Behind much of the reluctance to turn off the respirators in the Quinlan case in the United State. was concern over the possible criminal and civin liability of the medical staff involved. ${ }^{2}$

The bringing of a civil action against a nurse whP fails to take all reasonable steps to ensure the continuation of a patient's life is similarly feasible? In both cases a nurse may attempt to shelter unde? a 'respondeat superior' argument and place a responsibility with the doctor, but in theory there is no reason why she should succeed with this approach. ${ }^{3}$ The specific assumption in the Cod of responsibility for the 'total effects of medical

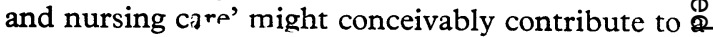


court's unwillingness to relieve a nurse of any degree of responsibility for her actions. The explanatory text refers to the duty of a nurse to question life-sustaining procedures which impinge upon the dignity of the dying patient. This assumes that no adverse legal consequences will flow from the withdrawal of these procedures, an assumption which I have suggested is currently unjustified.

The question of the patient's autonomy is directly raised in two sections of the Code, II.3, which stresses autonomy during illness, and II.4, which deals with the safety aspects of, inter alia, experimentation. Autonomy tends to be as difficult a concept in concreto as it is in abstracto. Section II.3 refers to 'open and sensitive communication', but the explanatory text declines to deal with the difficult issue of the patient's right to know. Some codes now stress the patient's right to information about his condition, ${ }^{4}$ but in the absence of such guidance the law is far from clear. A clear expression in the Rcn Code of the patient's right to information and a more explicit rejection of paternalism might influence the development of a firmer legal principle of the requirement of a full and informed consent to treatment.

Informed consent in the context of human experimentation, a hardy annual of much medicolegal debate, could well be stressed to a greater degree than it is in the current discussion document. The explanatory text stresses the right of the nurse to question the design of an experiment which involves discomfort or risk to patients, but the implications of the phrase 'experimentation without proper consent' are not expanded upon. The express eschewal of 'legal formulae' is certainly understandable, but in the light of the legal and ethical confusion surrounding this question there might have been more discussion of the concept of 'voluntary and informed' consent. The expression 'proper consent' is superficially adequate, but behind it lies a sea of juridical problems. Should experimentation ever be allowed when the subject is institutionalized in any way? (The disclosures of experimentation on prisoners and residents of homes for old people in the United States have raised fundamental ethical and legal problems.) Moreover, what degree of risk should the subject be allowed voluntarily to assume? These are questions which, given the assumption by nurses of responsibility for the wefare of those they nurse, are of direct concern to any nurse involved in experimental procedures.

Apart from those circumstances in which a nurse has a particular responsibility for the welfare of those in her care, she can, of course find herself faced with the Levite/Samaritan choice in respect of members of the general public. In view of the appalling absence of 'good samaritan' legislation in English-speaking countries, ${ }^{5}$ it might be argued that the gap should be filled wherever possible by the clear expression of a duty to render assistance to the injured (something on which the Code is silent). In the western European legal tradition, the duty to rescue is clearly stated in the criminal codes; in the Anglo-American legal systems no such duty exists. In the latter systems there is therefore no obligation to aid those in need of assistance, and in law this applies both to doctors and nurses. A forceful rejection of this unsatisfactory principle by the professions most intimately concerned might help to persuade the law to abandon its unfortunate and unconscionable stance.

\section{References}

${ }^{1}$ Robertson, J A, Involuntary Euthanasia of Defective Newborns: A Legal Analysis, Stanford Law Review, 1974, 27, 213-269.

${ }^{2}$ Note, The tragic choice: termination of care for patients ? in a permanent vegetative state, New York University Law Review, 1976, 51, 285-310.

${ }^{3}$ Some Canadian decisions have stressed that provided the nurse does as she is instructed, she will not be held civilly liable. On this, see Bernardot, $A, \mathrm{La}$ responsibilité civile de l'infirmière, Revue de Droit Université de Sherbrooke, 1972, 3, I-4I, at p. II. This view does not necessarily represent prevailing legal opinion.

${ }^{4}$ American Hospital Association's Statement on a Patient's Bill of Rights, I972. See Kornprobst, L, Les droits de l'homme malade devant les nouveaux programmes therapeutiques. Rapport juridique, Revue des droits de l'homme, 1974, 7, 528-540.

${ }^{5}$ Rudzinski, A, The duty to rescue: a comparative analysis in Ratcliffe, J, The Good Samaritan and the Law, Doubleday, New York, 1966. 